\title{
General cognitive, executive and memory function in children with hypoxic ischaemic encephalopathy (HIE) who underwent hypothermia treatment (TH)
}

Rina Cianfaglione', Brigitte Vollmer', Caroline Edmonds²

${ }^{1}$ Clinical Neurosciences, Clinical and Experimental Sciences, Faculty of Medicine, University of Southampton, UK 2 School of Psychology, University of East London, UK

Conclusions

Initial findings indicate that children with HIE treated with TH, without severe neuromotor impairment have IQ scores in the normal range. These results are in line with some findings from pre TH studies. Our findings suggest that children with HIE treated with TH without severe neuromotor impairment have particular difficulties with everyday memory. Impairment in everyday memory can have a great impact on the child's day-to-day activities and school experience and in the child's ability to retain information learned at school. This study emphasises the importance of follow up for children with neonatal HIE without a history of severe neuromotor impairment beyond toddler age, in particular the need to identify those children that experience subtle problems, which may have subsequent impact on the child self-confidence and self esteem.

\section{Background \& Aims}

Peripartum asphyxia with subsequent hypoxic ischaemic encephalopathy (HIE) is a significant problem, with an incidence between 1.5-1.6 per 1000 births in the UK. This condition is associated with disrupted oxygen flow in the brain with subsequent increased risk for brain injury and is treated with therapeutic hypothermia $(\mathrm{TH})$.

However, despite TH, which has reduced mortality and severe neurodevelopmental morbidity, children with HIE remain at risk for neurodevelopmental impairment.

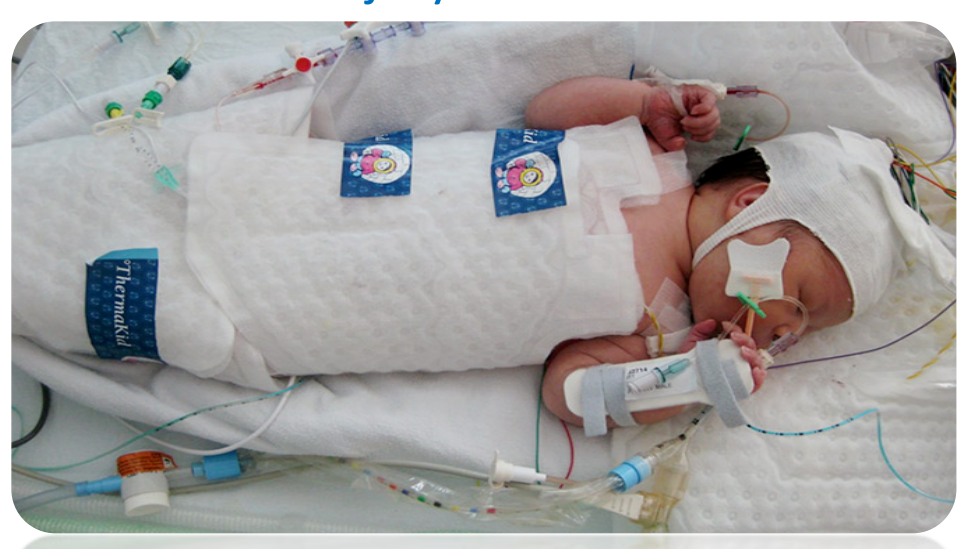

There is evidence which suggests that children with HIE who do not develop severe neuromotor impairment (Cerebral Palsy) experience difficulties in areas important for learning, such as general cognitive abilities, memory and executive functioning. Children with a history of HIE without severe neuromotor impairment treated with $\mathrm{TH}$ are understudied, particularly at school age. Moreover, there is a lack of studies comparing children with HIE with typical developing children without a history of HIE.

Aims:

- To report general cognitive, executive functions and memory abilities in children with HIE who underwent TH and survived without severe neuromotor impairment

- To compared the HIE children with a group of children without a history of HIE.

\section{Methods}

\section{Participants}

Children with a history of neonatal HIE and TH

- Recruited from a clinical cohort of children who had neonatal HIE and received hypothermia treatment

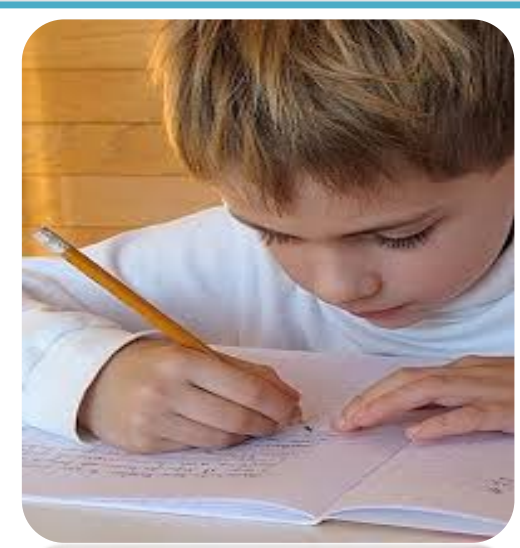
at Princess Anne Hospital, Southampton, UK, a tertiary neonatal centre.

- Born >36+6 weeks gestational age between 2009- 2013

- No severe neuromotor impairments (normal neurology or CP with GMFCS $<2)$

- Age between 5-7 years old at time of assessments (mean 5.04; SD 0.42)

Typically developing children without history of neonatal HIE

- Recruited from the same school as the children with HIE

- Matched by age and gender

Measures

- Wechsler Preschool and Primary Scale of Intelligence IV (WPPSI-IV) to assess general cognitive abilities (Full Scale IQ, FSIQ)

- Developmental Neuropsychological Assessment II (NEPSY-II) for Auditory Attention and Inhibition to assess selective and sustained attention

- Rivermead Behavioural Memory test (RBMT-C) to assess everyday memory.

\section{$\underline{\text { Results }}$}

A total of 33 children with Neonatal HIE treated with TH and 11 children without an history of HIE were included.

Table 1: Participants' characteristics

\begin{tabular}{|l|l|l|}
\hline & HIE (=33) & Control (=11) \\
\hline Gender & $\begin{array}{l}\mathrm{F}=18(54.5 \%), \mathrm{M}=15 \\
(45.5 \%)\end{array}$ & $\begin{array}{l}\mathrm{F}=9(81.8 \%), \mathrm{M}=2 \\
(18.2 \%)\end{array}$ \\
\hline $\begin{array}{l}\text { Mean chronological } \\
\text { age (years months) }\end{array}$ & $\begin{array}{l}5 \text { years 5 months (SD } \\
0.42)\end{array}$ & $\begin{array}{l}5 \text { years 7 months (SD } \\
0.53)\end{array}$ \\
\hline
\end{tabular}

Table 2: General cognitive functions

\begin{tabular}{|c|c|c|c|}
\hline WPSSI-IV^ & Group & Mean (SD) & $\begin{array}{c}\text { \% in the borderline and } \\
\text { score* }\end{array}$ \\
\hline FSIQ & HIE & $93.9(13.3)$ & $38.7 \%$ \\
\hline & Control & $100.7(14.6)$ & $20.0 \%$ \\
\hline VCI & HIE & $94.5(12.0)$ & $35.5 \%$ \\
\hline & Control & $96.1(11.7)$ & $40.0 \%$ \\
\hline & HIE & $87.1(15.3)$ & $45.5 \%$ \\
\hline & Control & $97.9(13.1)$ & $30.0 \%$ \\
\hline
\end{tabular}

$\wedge^{\wedge}$ orm Mean $(S D)=100(13) *$ Composite score $<90$

Table 3: Attention and Inhibition

\begin{tabular}{|c|c|c|c|}
\hline NEPSI-II^ & Group & Mean (SD) & \% Impaired score * \\
\hline $\begin{array}{c}\text { Auditory } \\
\text { Attention }\end{array}$ & HIE & $9.0(2.9)$ & $27.6 \%$ \\
\hline \multirow{2}{*}{ Inhibition } & Control & $12.8(3.1)$ & 0 \\
\hline & HIE & $10.0(3.1)$ & $14.1 \%$ \\
\hline CNorms mean (SD) $=15(3) ;{ }^{*}$ Scale score 8 & & $11.2(3.3)$ & $12.5 \%$ \\
\hline
\end{tabular}

Table 4: Everyday memory

\begin{tabular}{|c|c|c|c|}
\hline RMBT-CA & Group & Mean (SD) & $\begin{array}{c}\% \text { in the borderline/impaired } \\
\text { score* }\end{array}$ \\
\hline \multirow{2}{*}{$\begin{array}{l}\text { Total } \\
\text { score }\end{array}$} & HIE & $14.2(2.7)$ & $\begin{array}{l}\text { Borderline - } 50.0 \% \\
\text { Impaired - } 10.7 \%\end{array}$ \\
\hline & Control & $16.5(1.7)$ & $\begin{array}{l}\text { Borderline - } 10 \% \\
\text { Impaired - } 0\end{array}$ \\
\hline
\end{tabular}

\section{Acknowledgement}

We would like to thanks Sir Halley Stewart Trust for funding this project and all the children, families and schools that have supported us during the project. 